\title{
Nineteen-years of pneumococcal invasive disease surveillance in a children's hospital in Mendoza, Argentina
}

\author{
Héctor José Abate, M.D. ${ }^{a}$, Andrea Falaschi, M.D. ${ }^{a}$, Laura Balbi, Biochemist ${ }^{b}$, and Beatriz García, Biochemist ${ }^{b}$
}

\begin{abstract}
Five hundred and thirty-seven children admitted to Hospital Dr. Notti and diagnosed with invasive pneumococcal disease between 1993 and 2011 were studied. Their median age was 19 months (range $=0-192$ months); $34.82 \%$ were $<1$ year old and $23.46 \%, \geq 60$ months old. Pneumonia with or without effusion $(48.04 \%)$ and meningitis $(29.05 \%)$ were the most predominant conditions, with a case fatality rate of $6.14 \%$. Identified serotypes corresponded to 14,5 and 1 in $56.86 \%$ of cases. Sensitivity to penicillin was observed in $99.74 \%$ of non-meningeal strains, while sensitivity to ceftriaxone was found in $98.08 \%$ of meningealstrains. Risk factorsin pneumonia witheffusion were associated to age $\geq 60$ months old, RR: 1.47 (1.06-2.04), $p=0.02$, to serotype 5, RR: 2.57 (1.71-3.87), $p=0.0001$, and to serotype 1, RR: $1.86(1.17-2.96), p=0.014$; in the case of meningitis, risk factors were mainly associated to age $<1$ year old, RR: 2.35 (1.87-3.06), $p=0.0000$, and to serotype 18C, RR: 2.19 (1.3-3.7), $p=0.024$.

Conclusion. Streptococcus pneumonia was a major problem in infants younger than oneyear old, whopredominantly developed meningitis which caused half of deaths, and in children older than 60 months old, who had a prevalence of pneumonia with effusion. Most cases were sensitive to penicillin and ceftriaxone. Key words: invasive pneumococcal disease, serotypes, antibiotic sensitivity, risk factors.
\end{abstract}

http:/ /dx.doi.org/10.5546/aap.2014.eng.352

\section{INTRODUCTION}

Streptococcus pneumoniae (Spn) causes vaccinepreventable diseases with a high mortality rate. ${ }^{1} \mathrm{~A}$ review of data from Latin America and the Caribbean collected between 1990 and 2006 showed that between 12000 and 28000 children younger than 5 years old could die every year because of this disease. ${ }^{2}$

Serotypes that cause most invasive pneumococcal diseases (IPDs) show variations

a. Department of Infectious Diseases.

b. Department of Microbiology.

Hospital Pediátrico Dr. Humberto Notti.

Guaymallén. Mendoza. Argentina.

E-mail Address:

Héctor José Abate, M.D.: hjabate@gmail.com

Conflict of Interest: None.

Received: 7-31-2013

Accepted: 3-12-2014 in terms of geographic regions and type of disease,${ }^{3}$ in addition to changes in antimicrobial susceptibility, specially to penicillin and thirdgeneration cephalosporins. ${ }^{4}$ In Argentina, according to data collected by the Surveillance System for Bacterial Agents Responsible for Pneumonia and Meningitis (SIREVA), 2012, 79.2\% of identified meningitis strains and $100 \%$ of nonmeningeal strains were sensitive to penicillin in children younger than 5 years old. In the case of ceftriaxone, $94.3 \%$ were sensitive in meningitis, with an intermediate sensitivity (IS) of 5.7\%, while $98.5 \%$ were sensitive in non-meningeal conditions, with an IS of $1.5 \% .^{5}$

In 2012 (Resolution 502/2011), Argentina introduced the 13-valent pneumococcal conjugate vaccine (PCV13) to the immunization schedule for infants as of 2 months old. ${ }^{6}$ Knowing the epidemiology of IPD, the distribution of serotypes and antimicrobial susceptibility is essential to assess the potential impact of an immunization program.

\section{OBJECTIVES}

To describe the epidemiological characteristics of hospitalized patients with IPD and to detect risk factors for IPD.

\section{POPULATION AND METHODS}

Observational, analytical and retrospective study conducted between January 1993 and December 2011.

All patients with confirmed IPD diagnosis admitted to Hospital Pediátrico Dr. Humberto Notti, Mendoza, were selected. Confirmed IPD was defined as isolation of Spn in typically sterile liquid and a compatible clinical presentation.

Medical records were reviewed using the files from the Department of Microbiology, and a form was filled in with demographic data, clinical presentation, underlying disease, isolation site of Spn, antibiotic susceptibility, serotype, and case fatality rate.

During the study, serotyping was conducted using the Neufeld-Quellung test at the Department of Clinical Bacteriology INEIANLIS Dr. Carlos Malbrán, while the minimum 
inhibitory concentration (MIC) for penicillin and ceftriaxone was established using the E Test; values were adjusted according to cut-off points established by the Clinical and Laboratory Standards Institute (CLSI) in 2008. ${ }^{5}$

Quantitative outcome measures were expressed as median and range, and qualitative outcome measures, as percentage.

An univariate analysis was performed using the Epidat software, version 3.1, to assess risk factors for IPD, which reported the relative risk (RR), the $95 \%$ confidence interval $(95 \% \mathrm{CI})$, and a significant $p$ value $<0.05$.

The study was approved by Hospital Dr. H. Notti Ethics Research Committee and it was not necessary to sign an informed consent. The confidentiality of patient's identity was warranted.

\section{RESULTS}

Five hundred and thirty-seven children with IPD were included, with an annual mean proportion of 18.53 cases every 10000 hospital discharges (range: 7.82/10 000-35.66/10 000).

Table 1 shows some of the clinical characteristics of the studied population.

Considering all patients, $34.82 \%$ (n: 187) were $\leq 11$ months old; $19.36 \%$ (n: 104) were bewteen 12 and 23 months old; $10.80 \%$ (n: 58) were bewteen 24 and 35 months old; $6.70 \%$ (n: 36 ) were bewteen 36 and 47 months old; $4.84 \%$ (n: 26) were bewteen 48 and 59 months old; and $23.46 \%$ (n: 126) were $\geq 60$ months old.

Clinical presentations by age group are shown in Figure 1.

An underlying disease was present in $4.10 \%$ (n: 22) of children, distributed as nephrotic syndrome: 8 ; neoplasm: 7; immunodeficiency: 2; HIV: 1; cochlear implant: 1 ; cerebrospinal fluid (CSF) fistula: 1 ; chronic lung disease: 1 ; and heart disease: 1 .

According to the records, no subject had a history of pneumococcal vaccine or hospitalacquired IPD.

Through serotyping, 255 strains $(47.5 \%)$ were identified. Serotypes 14,5 and 1 accounted for $56.86 \%$ (n: 145 ) of all serotypes. Of the serotypes identified, $88 \%(225 / 255)$ are included in the PCV13. No circulating serotypes corresponded to serotypes 3 and 4 . Serotype distribution by age group is shown in Figure 2.

Among meningitis cases, $89.10 \%$ (n: 139) of strains were sensitive to penicillin; $98.08 \%$ (n: 153) were sensitive to ceftriaxone, and $0.26 \%$ (n: 1 ) had an IS. Among non-meningeal cases, 99.74\% (n: 380) were sensitive to penicillin, with an IS of $0.26 \%$ (n: 1 ); while $0.26 \%$ (n: 1 ) resulted in an IS to ceftriaxone.

Of all serotypes, $6.67 \%$ (n: 17) were resistant to penicillin, distributed as 14 (n: 8), 6B (n: 3), 19F (n: 2), 18C (n: 1), 9V (n: 1), 23F (n: 1), 23B (n: 1), with an IS to ceftriaxone of $1.18 \%$ (n: 3), accounted as serotypes 14 (n: 2) and 23F (n: 1).

Table 2 shows an analysis of the relative risk for each clinical presentation, by age, with no adjustment for comorbidities.

In infants younger than 1 year old, a significant association to serotypes 19F: RR: 2.01 (95\% CI: 1.35-3.0), $p: 0.01$, and 19A: RR: 2.48 (95\% CI: 1.86-3.30), $p: 0.0021$ was observed. In children $\geq 60$ months old, such association was found with serotype 1: RR: 3.05 (1.77-5.26), $p$ : 0.0004. For cases of pneumonia with effusion, an association was found with serotypes 5: RR: 2.57 (95\% CI: 1.713.87), p: 0.0001, and 1: RR: 1.86 (95\% CI: 1.17-2.96), $p: 0.014$. For cases of meningitis, an association was found with serotype 18C: RR: 2.19 (95\% CI: 1.3-3.7), $p: 0.024$.

TABLE 1. Characteristics of hospitalized patients diagnosed with invasive pneumococcal disease

\begin{tabular}{lc} 
N= 537 & \\
Median age, months (range) & $19(0-192)$ \\
Boys, $\mathrm{n}(\%)$ & $305(56.8)$ \\
\hline Clinical presentations & $156(29.05)$ \\
Meningitis, $\mathrm{n}(\%)$ & $136(25.32)$ \\
Pneumonia, $\mathrm{n}(\%)$ & $122(22.72)$ \\
Pneumonia with effusion, $\mathrm{n}(\%)$ & $71(13.22)$ \\
Bacteremia, $\mathrm{n}(\%)$ & $36(6.70)$ \\
Sepsis, $\mathrm{n}(\%)$ & $8(1.49)$ \\
Cellulitis, $\mathrm{n}(\%)$ & $6(1.12)$ \\
Arthritis, $\mathrm{n}(\%)$ & $2(0.37)$ \\
Primary peritonitis, $\mathrm{n}(\%)$ & \\
\hline Underlying disease & $22(4.10)$ \\
Total, $\mathrm{n}(\%)$ & $60(4-195)$ \\
Median age, months (range) & \\
\hline Case fatality rate & $33(6.14)$ \\
Overall, $\mathrm{n}(\%)$ & $18(54.54)$ \\
Due to meningitis, $\mathrm{n}(\%)$ & $8(24.24)$ \\
Due to sepsis, $\mathrm{n}(\%)$ & $7(21.21)$ \\
Due to pneumonia, $\mathrm{n}(\%)$ & \\
\hline
\end{tabular}


FIGURE 1. Clinical presentation by age group

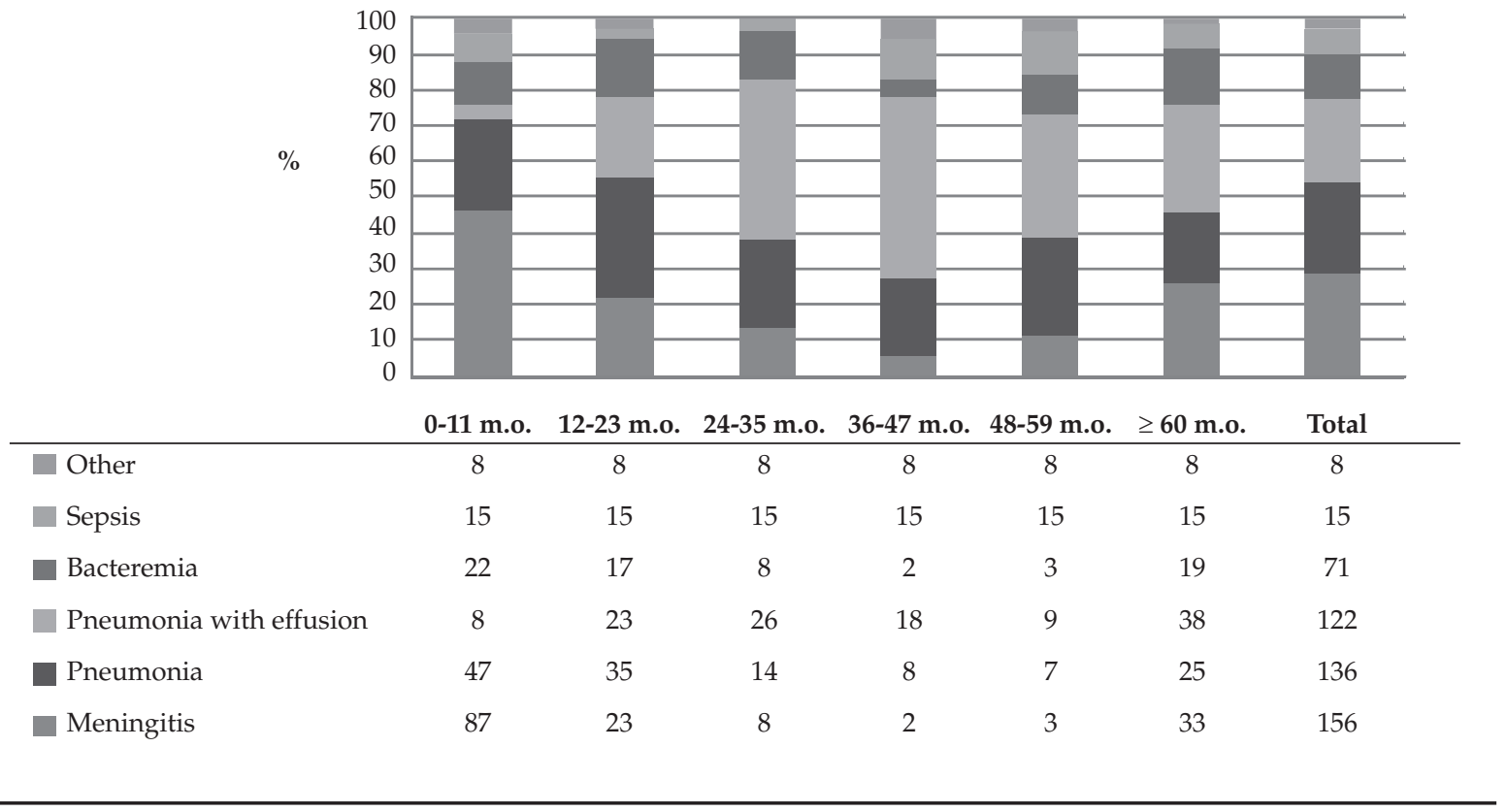

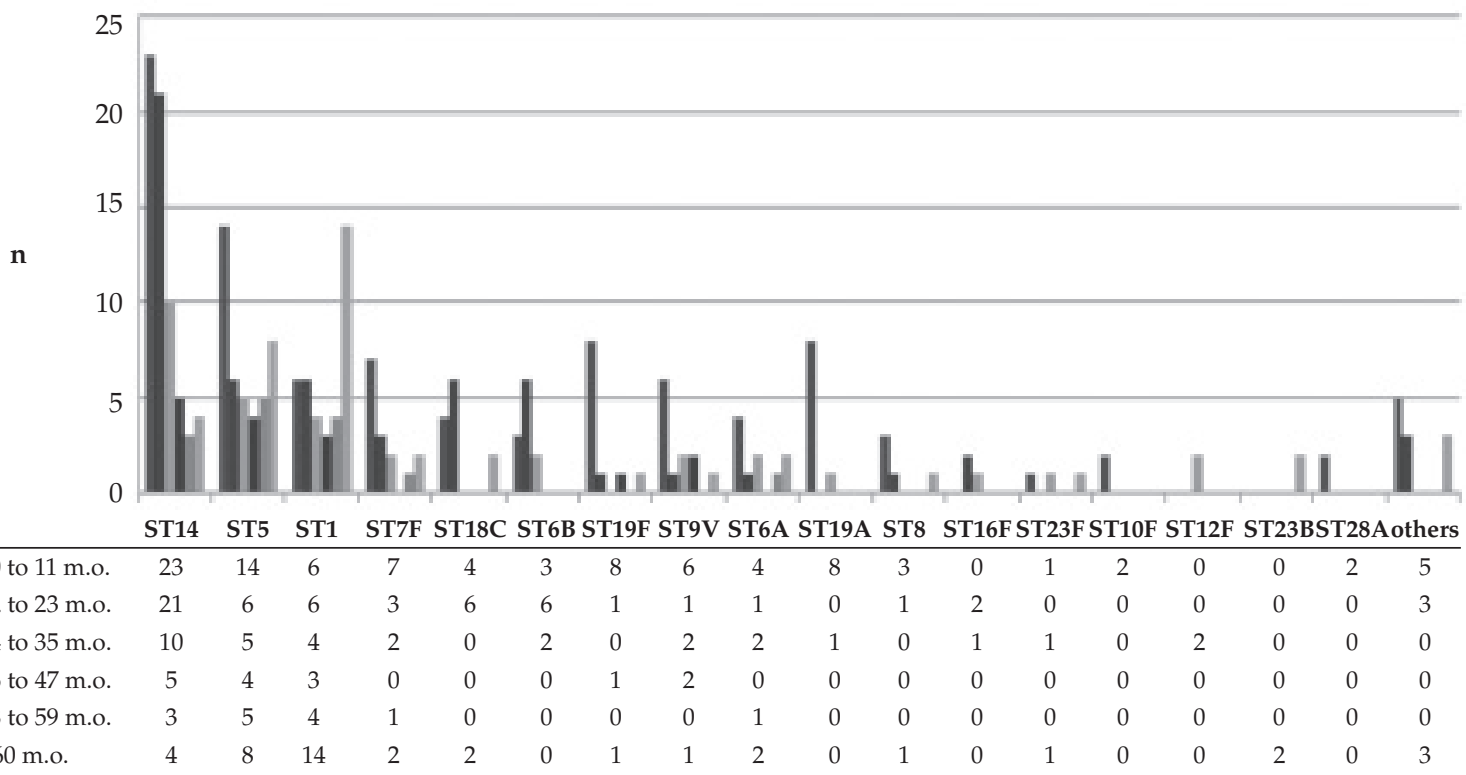

ST: serotype.

* Others with a ST: 11, 12, 16A, 18A, 18B, 2, 20, 35F, 42, 7C, 15B. 
A case fatality risk was observed in sepsis: RR: 4.45 (95\% CI: 2.16-9.15), $p$ : 0.0008; meningitis: RR: 3.46 (95\% CI: 1.67-7.16), p: 0.0007; and serotype 18C: RR: 3.37 (95\% CI: 1.21-10.54), $p$ : 0.05 .

\section{DISCUSSION}

This was a hospital-based study, and considering that approximately half of IPD cases require hospitalization, ${ }^{7,8}$ and that no outpatients with fever were included, the actual burden of IPD may have been underestimated. For this reason, prevalent conditions were meningitis and pneumonia with and without effusion, with a low frequency of bacteremias. ${ }^{9}$ This was also a limitation when analyzing the relative risk of having a certain age in relation to the different clinical presentations since the study included only seriously ill children.
Notwithstanding, and consistent with the literature from Latin America and the Caribbean, ${ }^{2,10}$ a higher incidence was observed in boys younger than 1 year old, showing an association with a higher risk of meningitis (RR: 2.35 [1.87-30.6], $p=0.0000)$ and serotypes $19 \mathrm{~F}$ and $19 \mathrm{~A}$. It is worth noting that, in the group $\geq 60$ months old, the percentage of IPD was high and showed a significant association with serotype 1 and pneumonia with effusion, which was also observed in other studies on wider age groups. ${ }^{11}$

When compared to other sites ${ }^{10,12}$ the percentage of subjects with an underlying disease was low, possibly in relation to the lesser complexity of hospitalized patients.

It should be noted that most strains were sensitive to ceftriaxone in meningeal conditions, and to penicillin in non-meningeal processes.

TABLE 2. Relative risk for each clinical presentation by age, with no adjustment for comorbidities

\begin{tabular}{|c|c|c|c|c|c|}
\hline Clinicalpresentation & Age & $\mathbf{N}$ & RR & CI (95\%) & $\mathbf{P}$ \\
\hline Meningitis & $<1$ year old & 87 & 2.35 & $1.87-3.06$ & 0.0000 \\
\hline \multirow[t]{5}{*}{ (N: 156) } & $<2$ years old & 110 & 2.02 & $1.49-2.72$ & 0.000 \\
\hline & $<3$ years old & 118 & 1.67 & $1.21-2.3$ & 0.006 \\
\hline & $<4$ years old & 120 & 1.34 & $0.97-1.85$ & NS \\
\hline & $<5$ years old & 123 & 1.14 & $0.82-1.58$ & NS \\
\hline & $>5$ years old & 33 & 0.87 & $0.63-1.21$ & NS \\
\hline Pneumonia & $<1$ year old & 47 & 0.98 & $0.72-1.34$ & NS \\
\hline \multirow[t]{5}{*}{ (N: 136) } & $<2$ years old & 82 & 1.28 & $0.95-1.73$ & NS \\
\hline & $<3$ years old & 96 & 1.29 & $0.93-1.98$ & NS \\
\hline & $<4$ yearsold & 104 & 1.28 & $0.95-1.81$ & NS \\
\hline & $<5$ yearsold & 111 & 1.36 & $0.92-2.00$ & NS \\
\hline & $>5$ yearsold & 25 & 0.73 & $0.49-1.07$ & NS \\
\hline Pneumonia with effusion & $<1$ yearold & 8 & 0.13 & $0.06-0.26$ & 0.000 \\
\hline \multirow[t]{5}{*}{ (N: 122) } & $<2$ yearsold & 31 & 0.28 & $0.19-0.41$ & 0.000 \\
\hline & $<3$ yearsold & 57 & 0.47 & $0.34-0.64$ & 0.000 \\
\hline & $<4$ yearsold & 75 & 0.63 & $0.46-0.86$ & 0.004 \\
\hline & $<5$ yearsold & 84 & 0.67 & $0.48-0.93$ & 0.02 \\
\hline & $>5$ yearsold & 38 & 1.47 & $1.06-2.04$ & 0.02 \\
\hline Others* & $<1$ yearold & 45 & 1.07 & $0.78-1.48$ & NS \\
\hline \multirow[t]{5}{*}{ (N: 123) } & $<2$ yearsold & 68 & 1.04 & $0.76-1.42$ & NS \\
\hline & $<3$ yearsold & 78 & 0.93 & $0.67-1.28$ & NS \\
\hline & $<4$ yearsold & 86 & 0.91 & $0.66-1.28$ & NS \\
\hline & $<5$ yearsold & 93 & 0.95 & $0.66-1.36$ & NS \\
\hline & $>5$ yearsold & 30 & 1.05 & $0.73-1.75$ & NS \\
\hline
\end{tabular}

NS: not significant. RR: relative risk. CI: confidence interval. 
Based on these data, it is relevant to continue using these antibiotics in Spn infections.

One of the limitations of this study was that it did not analyze the length of stay, progression or sequelae. However, the study recorded the case fatality rate, an indicator of disease severity, its value was considered intermediate when compared to other regions, $, 10,12$ an a risk four times higher for sepsis and three times higher for meningitis and serotype 18C.

Serotypes 14, 5 and 1 accounted for more than half of all identified serotypes, as observed in most Latin American countries. ${ }^{2,5,9,13}$ Although serotypes 3 and 4 , which are included in the PCV13, were not found in our cases, the vaccine does include most circulating serotypes related to resistance, except for $23 \mathrm{~B}$, which is less prevalent. Therefore, it is expected that the PCV13, recently introduced in Argentina, will achieve a major reduction in IPDs, as documented in other countries that introduced the 7-valent pneumococcal conjugate vaccine (PCV7). ${ }^{14,15}$ For this reason, it is important to continue collecting data on IPDs, both at a national and regional level, and considering the different variations.

\section{CONCLUSIONS}

IPD is a major problem among children in Mendoza, specially infants younger than 1 year old, in whom meningitis was predominant, and in children older than 60 months old, who showed a higher occurrence of pneumonia with effusion. A small percentage of patients had comorbidities, and more than half of all deaths were caused by meningitis. Most Spn cases were sensitive to penicillin and ceftriaxone.

\section{REFERENCES}

1. Black RE, Cousens S, Johnson HL, Lawn JE, et al. Global, regional, and national causes of child mortality in 2008: a systematic analysis. Lancet 2010;375(9730):1969-87.

2. Valenzuela MT, O'Loughlin R, De la Hoz F, Gomez E, et al. The burden of pneumococcal disease among Latin American and Caribbean children: review of the evidence. Rev Panam Salud Publica 2009;25(3):270-9.

3. Hausdorff WP, Siber G, Paradiso PR. Geographical differences in invasive pneumococcal disease rates and serotype frequency in young children. Lancet 2001;357(9260):950-2.

4. Cartwright K. Pneumococcal disease in Western Europe: burden of disease, antibiotic resistance and management. Eur J Pediatr 2002;161(4):188-95.

5. Grupo de Trabajo de SIREVA II. Informe regional de SIREVA II 2012: datos por país y por grupos de edad sobre las características de los aislamientos de en procesos invasores. Washington, DC: OPS 2013. [Accessedon: March 12, 2014]. Available at: http://www.paho.org/hq/index. php?option=com_content\&view $=$ category\&layout=blog\& $\mathrm{id}=3609 \&$ Itemid $=3953 \&$ lang $=$ pt.

6. Programa Nacional de Control de Enfermedades Inmunoprevenibles. Ministerio de Salud. Presidencia de la Nación. Introducción de la vacuna conjugada contra neumococo al Calendario Nacional de Inmunizaciones de la República Argentina. Lineamientos técnicos. Argentina, 2011. [Accessed on: March 12, 2014]. Available at: http:// www.msal.gov.ar/neumococo/descargas/lineamientosneumococo-25-11-2011.pdf.

7. Abarca K, Vergara R, Tassara E, Ibáñez I, et al. Infección neumocócica invasora y neumonía consolidante en lactantes: un año de vigilancia en tres centros hospitalarios chilenos. Rev Chil Infect 2008;25(2):97-103.

8. Lagos R, Muñoz A, Valenzuela M, Heitmann I, Levine MM. Population based surveillance pediatric invasive pneumococcal disease in Santiago, Chile. Pediatr Infect Dis J 2002;21(12):1115-23.

9. Tregnaghi M, Ceballos A, Rüttimann R, Ussher J, et al. Active epidemiologic surveillance of pneumonia and invasive pneumococcal disease in ambulatory and hospitalized infants in Córdoba, Argentina. Pediatr Infect Dis J 2006;25(4):370-2.

10. Ulloa-Gutierrez R, Avila-Aguero M, Herrera M, Herrera $\mathrm{J}$, Arguedas A. Invasive pneumococcal disease in Costa Rican children: a seven year survey. Pediatr Infect Dis J 2003;22(12):1069-74.

11. Guzvinec M, Tesovic G, Tambic-Andrasevic A, ZidovecLepej S, et al. The epidemiology of invasive Streptococcus pneumoniae disease in Croatian children. Med Sci Monit 2008;14(2):59-64.

12. Pérez GM, Parra A, Casimir L, Mastroiani A, el al. Infecciones invasivas por Streptococcus pneumoniae en un hospital pediátrico de tercer nivel antes de la introducción de la vacuna conjugada. Características clínicas y serotipos involucrados. Arch Argent Pediatr 2013;111(3):202-5.

13. Reijtman V, Fossati $S$, Hernández $C$, Sommerfieck $P$, et al. Serotype distribution of pneumococci isolated from pediatric patients with acute otitis media and invasive infections, and potential coverage of pneumococcal conjugated vaccines. Rev Argent Microbiol 2013;45(1):27-33.

14. Arguedas A, Soley C, Abdelnour A. Prevenar experience. Vaccine 2011;29(Suppl 3);C26-34.

15. Fitzwater SP, Chandran A, Santosham M, Johnson HL. The worldwide impact of the seven-valent pneumococcal conjugate vaccine. Pediatr Infect Dis J 2012;31(5):501-8. 